\title{
El trabajo de ADABI en el rescate y organización de archivos históricos municipales de México
}

\author{
María Areli González Flores \\ Apoyo al Desarrollo de Archivos y Bibliotecas de México, A.C. \\ agonzalez@adabi.org.mx
}

\section{Resumen}

Este artículo presenta el trabajo que la asociación civil Apoyo al Desarrollo de Archivos y Bibliotecas de México, A.C. (ADABI) realiza en el rescate y organización de archivos históricos municipales en la República Mexicana, desde su fundación en el año 2003 hasta la fecha. Durante poco más de una década de trabajo, la asociación ha apoyado el rescate de 124 archivos municipales en estados como Puebla, Oaxaca, Veracruz, Tlaxcala, Morelos y otros más. De acuerdo con su misión (preservar la memoria histórica de México depositada en archivos de dependencias gubernamentales como estatales o municipales), $A D A B I$ ha logrado el reconocimiento de diversas instituciones tanto a nivel nacional como internacional, avalando la metodología y profesionalismo con los que se desempeña en cada proyecto.

Palabras clave: $A D A B I$, archivos municipales, rescate

\section{Abstract}

This essay presents the work that is done to save as well as organize the history municipality files all over the Mexican Republic by Apoyo al Desarrollo de Archivos y Bibliotecas de México, A.C. (ADABI) from its foundation in 2003 up to now.

During more than a decade of Operation, the association has support 124 municipality files to be saved in the states of Puebla, Oaxaca, Veracruz, Tlaxcala, Morelos and some others. Due to its mission (preserve the historical memory of Mexico deposits in government, state or municipality offices), ADABI has achieved recognition of different International and National Governments, endorsing the methodology and professional execution of each project.

Keywords: $A D A B I$, municipal archives, recovery 


\section{Introducción}

El objetivo de este artículo es presentar el trabajo que Apoyo al Desarrollo de Archivos y Bibliotecas de México A.C. (ADABI) ha realizado en los archivos municipales mexicanos, los cuales resguardan documentos históricos cuya información es elemental para reconstruir el pasado de las poblaciones. Hasta la fecha no se ha elaborado una revisión que se centre en los archivos municipales apoyados por la asociación, de ahí que este texto busque llenar ese vacío, y a su vez, sea un atento llamado para señalar las necesidades que estos archivos tienen con respecto a su organización, resguardo e inventario.

Este trabajo contextualiza y presenta los antecedentes en materia de archivos municipales para entender el surgimiento de ADABI. Inicia con las definiciones de municipio y archivo; continúa con la cuantificación de los archivos municipales en el país, a través de los datos del Censo-Guía de Archivos de España e Iberoamérica, para dar paso a los antecedentes de su rescate emprendido por el Archivo General de la Nación (AGN). El último apartado está destinado a ADABI y su apoyo a los archivos municipales históricos, retoma la razón de ser de esta asociación, la metodología empleada en el rescate documental, el trabajo en equipo realizado con otras instituciones, así como los resultados obtenidos.

\section{Definiciones: el municipio y el archivo}

El municipio es la base de la división territorial y el cimiento de la organización política y administrativa de nuestro país, de acuerdo con lo establecido en el artículo 115 de la Constitución Política de los Estados Unidos Mexicanos. Los habitantes de cualquier estado de la República, antes de pertenecer a éste, tienen como vínculo más cercano el municipio, al cual se le han dado diversas definiciones desde el punto de vista jurídico, social e histórico.

El artículo 115 de nuestra Carta Magna también describe algunas de las características del municipio que ayudan a comprender su definición, como el hecho de administrarse por un ayuntamiento, 
o el estar investidos de personalidad jurídica propia y manejar su patrimonio conforme a la ley. De manera independiente prestan servicios públicos como agua potable, alumbrado, limpia, mercados y centrales de abasto o de seguridad pública, además de administrar libremente su hacienda. Hay que agregar que el municipio es la asociación de vecindad constituida por vínculos locales fincados en el domicilio, asentada en un territorio jurídicamente delimitado, con derecho a un gobierno propio, representativo y popular. ${ }^{1}$

Como se mencionó anteriormente, el órgano de representación popular encargado de las tareas de gobernabilidad y administración de un municipio es el ayuntamiento, donde el presidente municipal es el ejecutor de las determinaciones y el titular de la administración pública municipal; el síndico, es quien tiene a su cargo la procuración, defensa y promoción de los derechos e intereses municipales, además de funciones hacendarias y de contraloría.

Respecto a la administración, las estructuras municipales son heterogéneas, es decir, en algunos casos se organizan en direcciones, departamentos, unidades o coordinaciones, a excepción de la secretaría y la tesorería que son órganos indispensables y típicos de los ayuntamientos. Por tanto, se puede considerar que la estructura básica de cualquier municipio es la presidencia municipal, la tesorería, la secretaria del ayuntamiento y la comandancia de policía. ${ }^{2}$

Existen tres elementos de la administración pública municipal: primero, el personal, que está integrado por los órganos de la administración y se les denomina servidores públicos; segundo, el material, o el conjunto de bienes muebles e inmuebles necesarios para realizar las actividades a cargo de la administración municipal; y tercero, el formal, constituido por los ordenamientos legales que regulan la estructura, funcionamiento, atribuciones y relaciones de los órganos encargados de la administración. El ayuntamiento puede crear dependencias administrativas necesarias para la operación de sus programas con las unidades necesarias para ello, de esta forma, la

${ }^{1}$ González Minchaca, Dámaris, "El Municipio en México”, p. 26.

${ }^{2}$ Idem. 
administración pública puede descentralizarse o desconcentrarse según convenga.

Conocer qué es el municipio, cómo está organizado y las funciones que desempeña, se comprende que que en la realización de sus acciones diarias genera, de forma natural y conforme con sus funciones, documentos que son evidencias legales, administrativas o contables, con los cuales se va integrando el archivo municipal, que pocas veces figura como órgano del ayuntamiento, pero es de suma relevancia. Para Francisco Fuster Ruiz un archivo es:

la institución donde se reúne uno o más conjuntos orgánicos de documentos, de cualquier fecha o soporte, producidos, recibidos y acumulados, como resultado del ejercicio de la función o actividad de una persona o entidad pública o privada, organizados y conservados científicamente, respetando su orden natural, en un depósito que reúna las debidas condiciones y atendido por personal capacitado, para servir al sujeto productor o a cualquiera persona, como testimonio de la gestión de actos administrativos y/o jurídicos, o como información para fines científicos o culturales. ${ }^{3}$

El Manual de Organización de Archivos Municipales señala que un archivo tiene tres acepciones:

- Conjunto de documentos sea cual fuere su forma y soporte material, producidos y recibidos por persona física o moral, organismo público o privado en el ejercicio de su actividad y que son conservados por sus creadores o por sus sucesores para sus propias necesidades, o bien transmitidos a una institución de archivos competente en razón de su valor archivístico.

- Institución responsable de la acogida, tratamiento, inventariado, conservación y servicio.

${ }^{3}$ Fuster Ruiz, "Archivística, archivo, documentos", pp. 9-10. 
- Edificio o parte de un edificio donde los documentos son conservados. ${ }^{4}$

En ambas definiciones el archivo es visto primero, como institución: un conjunto de documentos de cualquier fecha o soporte; y segundo, como el resguardo y la acción de conservación, además del inmueble.

El término archivo municipal también alude a la institución que lo generó, en este caso, al municipio que forma parte del Estado mexicano y que se integra al nivel estatal y federal. En los archivos de estas instancias se conservan los documentos administrativos de la colectividad nacional, en atención a esos niveles de gobierno, los cuales se consideran archivos públicos, porque surgen al amparo de los diferentes órdenes de gobierno que por ley se tienen que guardar. ${ }^{5}$ A partir de lo anterior, el archivo municipal es

El corpus documental de tipo histórico o administrativo perteneciente al ayuntamiento, y por extensión, el local donde se conserva. Si el municipio es la piedra angular de la organización política, su archivo constituye el apoyo inmediato de la función administrativa diaria, así como base y principio de la historia local. ${ }^{6}$

La existencia y regulación de los archivos municipales se ha establecido en leyes estatales de sistemas de archivo o en leyes orgánicas; en otras, se menciona la importancia de los documentos como en la Ley Federal sobre Monumentos y Zonas Arqueológicos, Artísticos e Históricos. En las leyes estatales de archivos los ayuntamientos - como sujetos obligados- son los responsables del manejo directo y conservación de los documentos que generan. La ley orgánica municipal de cada estado señala que los archivos de este nivel dependen del secretario, por ejemplo, como en

${ }^{4}$ ADABI, Manual de Organización de Archivos Municipales, p. 28.

${ }^{5}$ Salazar Adame, "Los archivos municipales", p. 453.

${ }^{6}$ Alanís Boyso, "Los archivos municipales del estado", pp. 567-568. 
el caso de los municipios de Puebla, Querétaro, Michoacán, Yucatán, Jalisco o Nuevo León, sólo por citar algunos; frente a otras leyes en las que ni siquiera aparece el archivo, como la Ley Orgánica Municipal del Estado de Sinaloa, o en el caso de Veracruz, cuya ley señala que el cronista dará asesoramiento histórico, cívico y cultural a quien se lo solicite por medio del archivo municipal.

La Ley Federal sobre Monumentos y Zonas Arqueológicos, Artísticos e Históricos establece que son monumentos históricos los documentos $\mathrm{y}$ expedientes que pertenezcan o hayan pertenecido a las oficinas y archivos de la Federación, de los estados o de los municipios y de las casas curiales, además de los documentos originales manuscritos relacionados con la historia de México y los libros, folletos y otros impresos en México o en el extranjero, durante los siglos XVI al XIX que por su rareza e importancia para la historia mexicana, merezcan ser conservados en el país.

Pese a la existencia de este marco normativo, la realidad de los archivos municipales en los estados refleja la omisión de la aplicación de estas leyes. El descuido o desinterés de los responsables es evidente cuando en vez de un archivo, se tienen bodegas o cuartos llenos de hojas de piso a techo donde se almacenan legajos de documentos junto a artículos de limpieza, objetos de festividades o aparatos de sonido, basura o residuos de comida. La situación empeora cuando están dañados por roedores o con excremento de animales. La humedad también provoca estragos ya que genera hongos en los papeles deteriorándolos incluso hasta destruirlos. Sin embargo, los daños más graves son los causados por el hombre ya que los mutila, roba, desaparece o quema al considerarlos viejos.

A esta situación se suman problemáticas que la administración municipal enfrenta, ${ }^{7}$ como la falta de presupuesto o de personal capacitado y la mala distribución de espacios de trabajo, entre otros. Esta situación en la administración pública es común para los archivos municipales y es que:

${ }^{7}$ Hernández Gutiérrez, "Hacia un diagnóstico general", p. 4. 
no han sido cabalmente protegidos por la ley en su carácter de objetos cotidianos portadores potenciales de información histórica indispensable para el reconocimiento, valorización y conservación del patrimonio artístico y cultural que no es otra cosa más significativa que nuestra identidad colectiva porque se orienta a cuatro funciones esenciales: la recolección de documentos, la conservación del patrimonio documental, el servicio a la investigación y la valoración de esa parte del patrimonio. ${ }^{8}$

Por estas razones, los archivos municipales deben ser rescatados del estado físico en el que se encuentran, pues constituyen parte de la memoria de las poblaciones que está en peligro de desaparecer.

Generalmente, los archivos municipales de las capitales de los estados o municipios metropolitanos ${ }^{9}$ son los que más apoyo tienen, dado que se asigna un presupuesto anual, personal adecuado e infraestructura de archivo; tienen una misión, visión, objetivos y un reglamento de consulta; el archivo aparece como dirección, departamento o jefatura en el que laboran entre cinco a diez personas, con ciertos conocimientos en archivística o con experiencia en archivo. En los municipios que se consideran semiurbanos o rurales, raramente se destinan recursos para el archivo o asigna personal para que se haga cargo, debido a que los pocos recursos con los que cuenta son destinados a otras obras.

${ }^{8}$ Salazar Adame, "Los archivos municipales", p. 451.

${ }^{9}$ Los municipios se han clasificado en metropolitanos, urbanos, semiurbanos y rurales, de acuerdo con la población que albergan, la formación del ayuntamiento, los servicios públicos y la educación que brindan. González Minchaca, "El Municipio", pp. 27-29. 


\section{Los archivos municipales en cifras}

Para entender la situación actual de los archivos mexicanos con respecto a su número, es necesario remitirse al Censo-Guía de Archivos de España e Iberoamérica - disponible en el portal del Ministerio de Educación, Cultura y Deporte del gobierno de España-. Este censo tiene el objetivo de integrar información sobre los archivos españoles, ampliado a otros países del ámbito hispano para registrar sus directorios, servicios y acervos en una base de datos normalizada, basada en la norma ISAD-G de descripción archivística. En este caso, el censo funciona como un parámetro con el que sabemos el número de archivos existentes en el país, aunque no el exacto, ya que tal vez algunos estén en funcionamiento sin aparecer en el registro.

En el censo se contabilizan hasta la fecha ${ }^{10} 1,274$ archivos divididos en generales y centrales, de congresos, judiciales, notariales, registro público, universitarios, religiosos; de asociaciones, empresariales, personales y familiares, partidos políticos y otros más (Gráfica 1).

Respecto a los archivos municipales hay 310 registros lo que equivale a $24 \%$ del total. Sin embargo, esta cifra es ínfima, equivalente apenas a $12 \%$, si la comparamos con los 2,457 municipios que existen en el país (Gráfica 2).

De estos 310 archivos, 184 son históricos, lo que equivale a $60.92 \%$ de los registros, es decir, más de la mitad; el resto corresponde a archivos generales, de trámite o concentración. El mayor número de archivos históricos registrados pertenece a Aguascalientes, con diez archivos de un total de 12 municipios, Guanajuato con 31 registros de un total de 46 municipios y el Estado de México con 71 de 125, es decir, poco más de la mitad.

Por otra parte, los estados de Guerrero, San Luis Potosí, Sinaloa y Tabasco no registran ningún archivo a pesar de que el AGN o ADABI apoyaron en el rescate de algunos de ellos. De los estados que superan

${ }^{10}$ Julio de 2015. 
Gráfica 1. Tipos y porcentajes de archivos mexicanos registrados en el Censo-Guía de Archivos de España e Iberoamérica. Fuente: elaboración propia a partir de los datos del Censo-Guía de Archivos de España e Iberoamérica y de los inventarios de ADABI.

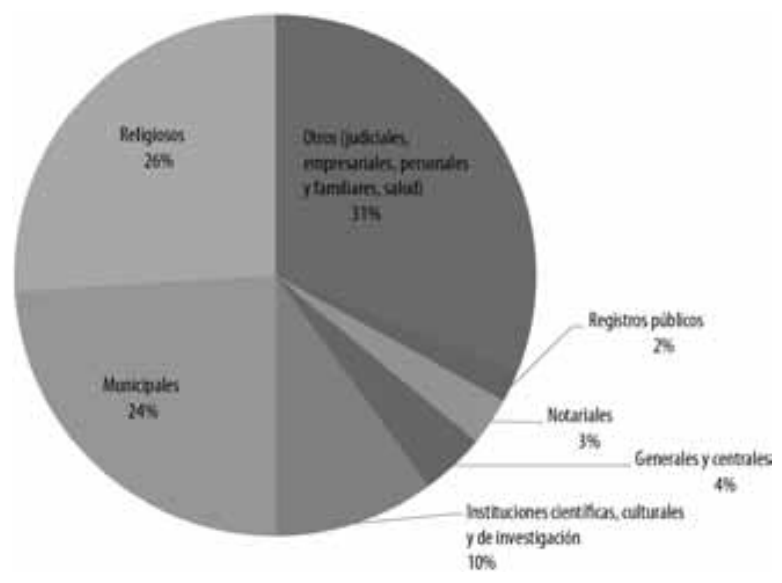

En los 100 municipios notamos que menos del diez por ciento de éstos tienen registros de archivos, por ejemplo, el estado de Oaxaca, con 570 municipios, apenas cuenta con 39 archivos municipales; en Puebla hay 17 archivos registrados de un total de 217 municipios, o Veracruz, donde de sus 212 municipios sólo dos cuentan con registro. Más preocupante es el caso de estados como Chiapas (123), Jalisco (125), Michoacán (113) o Yucatán (106), donde ninguno de sus municipios cuenta con este registro.

Estas cifras demuestran que a pesar de que se han realizado rescates y organización de archivos en los estados ya citados, las autoridades municipales no dieron continuidad al trabajo realizado ni tomaron acciones como nombrar a un responsable, designar un espacio o brindar el servicio de consulta tanto interno como externo. 
Gráfica 2. Porcentaje de archivos municipales registrados en el Censo-Guía de Archivos de España e Iberoamérica. Fuente: elaboración propia a partir de los datos del Censo-Guía de Archivos de España e Iberoamérica y de los inventarios de ADABI.

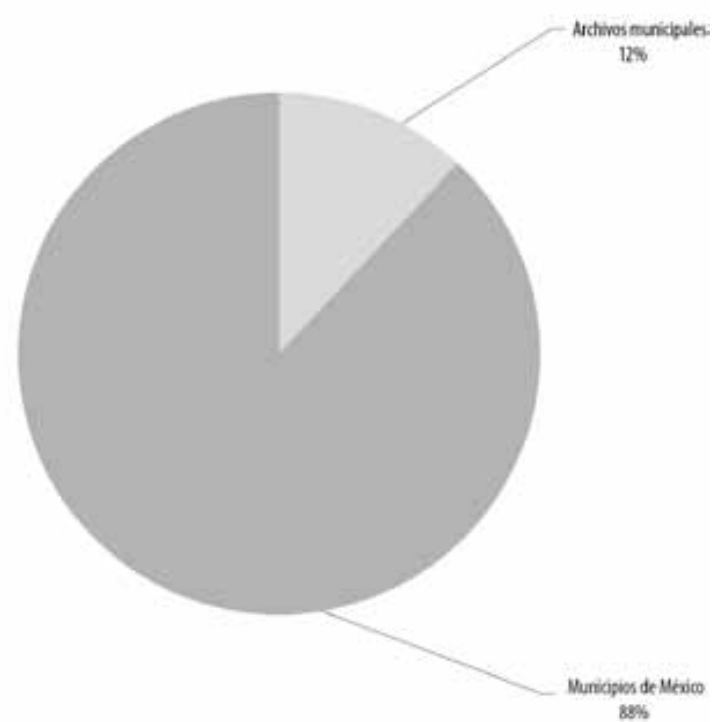

\section{Antecedentes de rescate de archivos municipales}

En México, durante las décadas de los sesenta y ochenta del siglo $\mathrm{Xx}$, se sentaron las bases del rescate y organización de archivos municipales. El punto de partida fue la celebración del Primer Seminario Nacional de Unidades de Correspondencia y Archivos Administrativos e Históricos de la Administración Pública Estatal y Municipal en la ciudad de Puebla, organizado por el AGN en 1977. De este evento surgió la necesidad de crear un Sistema Nacional de Archivos que respondiera a la urgente necesidad de atender los distintos espacios que custodian documentos en el país. La creación de este sistema, en 1978, tuvo una aplicación para los tres niveles de gobierno: el federal, el estatal y el municipal. Por primera vez se tomaron en cuenta los siguientes aspectos metodológicos: 
1. Que los archivos, especialmente gubernamentales, deberían funcionar de conformidad con un enfoque sistémico, esto es, como partes interactuantes para el cumplimiento de fines comunes.

2. Que era necesario respaldar la creación del Sistema Nacional de Archivos a través de un diseño conceptual coherente, sustentado metodológicamente en la teoría de sistemas.

3. La determinación del esquema organizativo del sistema, sus mecanismos de coordinación y operación y su funcionamiento integral, bajo la divisa de una centralización normativa y una descentralización operativa de los archivos.

4. La necesidad de formalizar la creación del sistema a través de un documento técnico y de cara a su pronta formalización jurídica. $^{11}$

Por aquellos años el AGN fue nombrado como el órgano normativo y de consulta para el Poder Ejecutivo en materia de archivos administrativos e históricos. A partir de este momento, esta institución promovió trabajos archivísticos en todo el país, con el fin de lograr la adecuada organización e interrelación de los repositorios documentales, así como el cumplimiento con los objetivos de servicio determinados por el sistema nacional, los cuales, abarcaron la amplia gama de tipologías de los archivos, es decir, los de la administración pública federal, estatal y municipal, los eclesiásticos y los privados.

Dentro de sus programas el AGN implementó uno dedicado al registro nacional de archivos históricos en todo el país ${ }^{12}$ que consistió en detectar el estado real de los archivos, entre estos, los municipales para preparar programas de rescate y organización. Los resultados obtenidos fueron el registro de 89 a 100\% de los archivos municipales de 19 estados de la República Mexicana, además del diagnóstico

${ }^{11}$ Ramírez Deleón, Metodología para la organización, p. 19.

${ }^{12}$ La doctora Stella María González Cicero coordinó este programa desde 1978 hasta 1982 en el AGN. Fue también responsable del programa de rescate y organización de archivos históricos. 
archivístico de 17 estados. Otro programa derivado del anterior fue el de rescate y organización de archivos históricos, con éste se sentó parte de las actividades que el AGN desarrolló para atender el rezago existente en archivos municipales a nivel nacional, considerando que los documentos se encontraban en pésimas condiciones físicas, a expensas de factores biológicos o humanos que podrían destruir.

Los primeros resultados fueron el rescate y organización de los archivos municipales del estado de Puebla, en el que intervinieron diferentes instancias como el gobierno del estado, los gobiernos municipales y el AGN, en octubre de $1983 .{ }^{13}$ Este proyecto fue un ejemplo para emprender el programa "Levantemos la historia del suelo", desarrollado de 1985 a 1998 por el AGN, en el que se rescataron y organizaron archivos históricos municipales en estados como Hidalgo, Querétaro, Estado de México, Aguascalientes, Tabasco, Sinaloa y Tamaulipas. ${ }^{14}$ Este programa atendió las fases de limpieza, clasificación en secciones, ordenación documental y su pertinente resguardo.

Las acciones desarrolladas por el AGN despertaron el interés de diferentes profesionistas e instituciones públicas, que vieron en los archivos un mundo de información que era necesario conocer a profundidad, ya que en estos se encuentra parte de la historia de México. Buscaron recursos económicos, becas o apoyos provenientes de instituciones públicas o privadas para invertirlos en tareas archivísticas.

Un ejemplo fue el proyecto "Fuentes y documentos para la historia de Puebla", programa de rescate, inventario y catalogación de archivos desarrollado en 1983 por el Centro de Investigaciones Históricas y Sociales del Instituto de Ciencias de la Universidad Autónoma de Puebla. Un equipo de trabajo catalogó los documentos del Archivo Municipal de Atlixco e inventarió los del Archivo Municipal de

${ }^{13}$ Rodríguez Ochoa, "Los archivos municipales de Puebla".

${ }^{14}$ El AGN publicó en la "Serie Archivos Estatales y Municipales" los inventarios de los archivos municipales de cada estado. 
Tecali y del Archivo Municipal de Tepeaca, además, se encargó de difundirlos para contribuir al aseguramiento de la integridad de los documentos y al aprovechamiento óptimo de los recursos de la investigación. ${ }^{15}$ Los recursos económicos de este proyecto se obtuvieron de los ayuntamientos, de la Universidad Autónoma de Puebla y del Programa Nacional de Educación Superior (Pronaes) de la Secretaria de Educación Pública.

El estado de Veracruz es un caso particular, ya que, a pesar de la propuesta de rescate y organización de archivos municipales que fue presentada al entonces gobernador del estado, Fernando González Barrios (1986-1988) por parte del AGN, en 1987 no fue aceptada. En ese mismo año, el Centro Regional INAH Veracruz, conformó un equipo de trabajo apoyado por el Centro de Estudios sobre la Universidad de la Universidad Nacional Autónoma de México, quienes rescataron y organizaron el Archivo Municipal de Tlacotalpan. ${ }^{16}$ Los documentos se organizaron por temas y fueron ordenados cronológicamente. De ese trabajo se obtuvo un inventario y se realizaron ensayos históricos sobre Tlacotalpan, que se compilaron en el libro Con el sello de agua. ${ }^{17}$ La tarea de rescate de los archivos históricos veracruzanos continuó con un grupo del Instituto Veracruzano de Cultura quienes rescataron 11 archivos municipales entre 1988 y 1994. Además, se realizaron capacitaciones sobre rescate y organización de archivos municipales, restauración, fumigación y conservación, microfilmación y reprografía, además de paleografía. Todos impartidos por personal del AGN y del Instituto de Investigaciones Estéticas de la Universidad Nacional Autónoma de México (UNAM). ${ }^{18}$

En el caso del Estado de México se convocó a la Primera Campaña Prosalvamento del Archivo Histórico del Estado de México y sus archivos municipales que inició en julio de 1993 con 140 voluntarios.

${ }^{15}$ Cruz Valdez, "Los archivos de Veracruz". pp. 111-113.

${ }^{16}$ Vergara Cruz, Los archivos de Veracruz.

${ }^{17}$ Lozano y Nathal, "Con el sello de agua".

${ }^{18}$ Vergara Cruz, Los archivos de Veracruz, p. 11. 
Este proyecto fue posible gracias al apoyo de instituciones educativas como preparatorias, normales, universidades y asociaciones civiles. ${ }^{19}$ En 1999, en Morelos, surgió el proyecto Archivo Histórico Digital del estado de Morelos (AHDEM) ${ }^{20}$ con el objetivo de digitalizar y salvaguardar los documentos depositados en los distintos archivos del estado. Sin embargo, este objetivo se modificó ya que en realidad se requería rescatar, organizar e inventariar antes que digitalizar. Entre 2001 a 2004, con el apoyo y asesoría del AGN y del Archivo Histórico del Arzobispado de México, se capacitó a un pequeño grupo de jóvenes de la licenciatura en Historia de la Universidad Autónoma del estado de Morelos, quienes rescataron archivos parroquiales y municipales.

Por su parte, el AGN siguió en su tarea de direccionar el trabajo archivístico en el país. De 1999 a 2003 impulsó el rescate de archivos históricos entre los que se encontraban los municipales. ${ }^{21}$ En 2000 se creó el fideicomiso "Preservación de la memoria de México", integrado por un grupo de particulares, empresarios, archivistas e intelectuales interesados en la historia del país. Los recursos extraordinarios generados por este fideicomiso (y que no provenían del presupuesto del AGN) se destinaron a programas de organización de fondos documentales, a preservación de documentación histórica, a difusión de los acervos y mejoramiento de los depósitos para documentos, todos, dirigidos por el AGN. Gracias a estos recursos se beneficiaron archivos en los estados de Baja California, Sinaloa, Puebla, Oaxaca y Campeche.

Específicamente, en el 2000 el Archivo General del estado de Puebla inició el programa Rescate y creación de los archivos municipales del estado de Puebla, con el apoyo del AGN y de la Secretaría de la Defensa Nacional (SEDENA) a través del Servicio Militar Nacional.

${ }^{19}$ Dorantes de Silva, "El estado que guardan el Archivo", pp. 143-145.

${ }^{20}$ Este proyecto lo inició la doctora María Alicia Puente Lutteroth (q.e.p.d) y del doctor Marcelo Ramírez Ruiz, ambos, profesores del Departamento de Historia de la Facultad de Humanidades de la Universidad Autónoma del Estado de Morelos (FHUAEM).

${ }^{21}$ Bajo la dirección de la doctora Stella María González Cicero. 
De 2000 a 2002 se rescataron archivos de la zona Mixteca Baja, Sierra Mixe y el Valle de Etla en Oaxaca. También se impartieron cursos en lugares como Huajuapan de León, la Heroica Ciudad de Tlaxiaco y San Pedro y San Pablo Teposcolula sobre organización de archivos municipales y documentos de trámite y concentración. ${ }^{22}$

\section{El apoyo de ADABI a los archivos históricos municipales de México}

A pesar de los esfuerzos emprendidos para el rescate de archivos municipales, éstos fueron insuficientes debido a que los programas o proyectos eran temporales y de recursos económicos limitados; y es que la necesidad de tener documentos organizados es una constante en todo el país. Sin estos antecedentes y la realidad en materia de archivos no se entendería la creación de ADABI de México, que surgió para aminorar los males de los archivos con sus programas de apoyo. Quien impulsó su fundación fue la actual presidenta, la doctora María Isabel Grañén Porrúa, consciente del patrimonio documental mexicano depositado en los archivos; su directora, la doctora Stella María González Cicero continúa su tarea de mejorar las condiciones físicas de los archivos emprendida en el AGN.

\section{Apoyo al Desarrollo de Archivos y Bibliotecas de México}

ADABI de México, como es conocida esta asociación civil, se creó el 9 de mayo de 2003 con el interés de contribuir a salvaguardar la memoria del país impulsando proyectos enfocados al rescate, preservación, valoración, investigación; difusión documental y bibliográfica, a favor de instituciones con pocos recursos, pero sin soslayar la formación profesional mediante cursos, apoyo y asesorías. ${ }^{23}$

${ }^{22} \mathrm{El}$ resultado de los trabajos realizados en Oaxaca son los textos El patrimonio documental oaxaqueño e Inventario de archivos municipales de Oaxaca.

${ }^{23}$ Para más detalles de estas acciones véase el sitio www.adabi.org.mx. 
La labor archivística de la asociación está a cargo de la Coordinación de Archivos Civiles y Eclesiásticos (CACE) que tiene el fin de rescatar y organizar archivos históricos civiles (municipales) y eclesiásticos (parroquiales), considerando que ambos son los de mayor vulnerabilidad en cuanto a su preservación en el país. Bajo la coordinación del maestro Jorge Garibay, el CACE coadyuva en la capacitación, difunde la cultura archivística y apoya la formación profesional en el ámbito nacional.

Esta coordinación desarrolla un trabajo archivístico importante a nivel municipal siendo un referente, debido a su compromiso por iniciar y culminar proyectos de rescate, así como el inventario, un instrumento de control y consulta archivística que orienta al investigador en la consulta del archivo.

Se entiende por rescate mejorar la situación física del archivo considerando que, en la mayoría de los casos, se encuentran en un estado de abandono a expensas de que factores intrínsecos o extrínsecos los destruyan. El interés de ADABI se ha centrado en archivos históricos, es decir, los documentos cuyo año extremo es 1950 ya que en ellos está depositada parte de la memoria histórica de las poblaciones; así, se han rescatado e inventariado documentos de siglos XV o XVI cuya existencia se desconocía.

Para que ADABI apoye en el rescate del archivo es necesario que el presidente municipal remita un oficio que solicite apoyo, posteriormente, se hace un diagnóstico para saber la situación física en que se encuentran, el número de cajas necesarias para resguardar los documentos, así como las fechas extremas. También mediante el diagnóstico se determina el apoyo a brindar, por ejemplo, una capacitación o el rescate documental.

El rescate de archivos se desarrolla en varias etapas. Al inicio los documentos se ubican en un mismo lugar, ya que a veces se encuentran dispersos en las instalaciones del municipio, como tapancos, cárceles o bodegas. Mediante una limpieza general se elimina el polvo o suciedad, como excremento de animales acumulado por el paso del tiempo. La limpieza se hace de manera cuidadosa con brochas en un espacio ventilado y con uso de guantes, cubrebocas y bata. 
La siguiente etapa es la organización, que incluye la clasificación en secciones y series documentales con base en un cuadro de clasificación archivístico. Generalmente un archivo municipal se clasifica en cuatro secciones: Gobierno, Hacienda, Justicia y Registro Civil, ${ }^{24}$ cada una con sus respectivas series documentales. Clasificarlos con orden es otra división de la organización donde se colocan cronológicamente los documentos de cada serie, del más antiguo al más reciente.

Posteriormente, a cada libro o expediente se le coloca el resguardo de primer nivel de papel cultural libre de ácido, se indica, en la parte superior derecha el nombre del archivo, la sección, serie, años y observaciones correspondientes. Enseguida viene el resguardo de segundo nivel, donde se archivan los documentos en cajas AG-12 enumeradas de forma ascendente, se les coloca una etiqueta provisional, al mismo tiempo, se elabora el inventario. Por último se colocan etiquetas finales a cada caja y se ubican en la estantería o lugar reservado. El inventario se elabora en un formato de Excel en el que se contemplan sección, serie, número de caja, número de volumen por caja, fechas extremas de cada caja y observaciones.

ADABI publica el inventario de cada archivo, acompañado de una breve historia del municipio en la que los documentos son la principal fuente de información, también se incluyen el cuadro de clasificación así como las fotografias de antes y después del trabajo. El municipio, los colaboradores y el coordinador de proyecto reciben ejemplares gratuitos de este inventario. De esta forma se cumple con los rubros que señala la norma internacional de descripción ISAD-G y se sientan las bases para la realización de otros instrumentos archivísticos, como son la guía y el catálogo, además de fomentar la investigación que contribuirá a enriquecer la historia regional.

Una vez que ADABI culmina la tarea de rescate, corresponde a las autoridades municipales en turno procurar que el archivo permanezca en condiciones asignándole un espacio definitivo al

${ }^{24}$ ADABI integra al archivo municipal los documentos de Justicia y Registro Civil consciente de que, aunque no son generados por el municipio, sí son susceptibles de destruirse. Si se integran al archivo se conservan. 
archivo, un responsable y facilidades para la consulta. En el caso de los rescates se le pide al ayuntamiento apoyar con los gastos de viáticos del personal que interviene en el proyecto, en tanto que la asociación aporta el papel cultural libre de ácido, las cajas AG-12 necesarias para el resguardo de los documentos, el salario de su personal y la publicación del inventario del archivo. Respecto a la capacitación, se orienta a un grupo de personas que se encargará de rescatar y organizar el archivo de acuerdo con la forma de trabajo de ADABI hasta obtener un inventario de los documentos.

En la actualidad se ha apoyado a 124 archivos históricos municipales en diferentes estados de la República Mexicana como se muestra en el Cuadro 1.

De acuerdo con el cuadro, en Puebla se ha trabajado con 34 archivos y 27 en Oaxaca; Chihuahua con 7, Morelos con 6, Tamaulipas con 4, Veracruz y Tlaxcala con 3 cada uno y por último Michoacán, Durango y San Luis Potosí con 1.

Con respecto a las fechas extremas de los documentos que resguardan estos archivos (véase Gráfica 3), 50\% inician en el siglo xix con un total de 62. Esto alude a que en este siglo el país se organizó y dividió después del proceso de Independencia, considerando al municipio como la base de la administración y división política - como se mencionó en la primera parte de este trabajo- ${ }^{-}$. De ahí le siguen los del siglo $\mathrm{xx}$, con un total de 26 archivos y los del siglo xvIII con 20. Los archivos del siglo xvII aparecen con un cinco por ciento con un total de seis, pero esta cifra aumenta en los del siglo Xvi con diez. Al señalar la cronología de algunos de los archivos se destaca la riqueza documental que se conservó gracias al rescate, pero también es un llamado para considerar cuántos archivos municipales más en el país están por desaparecer por falta de interés de las autoridades que los custodian.

Estos archivos han pasado y superado circunstancias adversas negándose a desaparecer, ya que en diversos municipios no falta el cronista, coleccionista o humanista, que ve en ellos parte de su historia. Ejemplo de esta situación es el Archivo Municipal de Tepoztlán, en Morelos, que durante la década de los sesenta el ayuntamiento en 
turno intentó destruir. El etnohistoriador Carlos Barreto, investigador del Centro INAH Morelos se enteró de esta situación y lo rescató, resguardándolo en el ex convento de Tepoztlán -donde actualmente se encuentra- y no en las instalaciones del municipio. Un caso similar ocurrió en el municipio de Ixtenco, en Tlaxcala, cuando en la década de los ochenta el ayuntamiento decidió tirar los documentos a la basura, sin embargo, se logró evitar y así hoy se constituye como el archivo histórico.

\section{Trabajo en equipo}

La labor de ADABI es fruto de esfuerzos propios y de instituciones que se han sumado como universidades o archivos estatales, ya que ven en la asociación la certidumbre para emprender convenios de colaboración, motivados por intereses en común. Un ejemplo es lo realizado en el Archivo General del Estado de Puebla (AGEP), el cual contó con el financiamiento de ADABI de 2003-2007. En Morelos a través del proyecto de Archivo Histórico Digital del Estado de Morelos, (AHDEM) se rescatan, organizan e inventarían archivos municipales y parroquiales.

Otro más fue el rescate de archivos históricos de la provincia zoque, siglos XVI al XXI; participaron ADABI y la Universidad de Ciencias y Artes de Chiapas (UNICACH), en 2012; se hicieron 25 diagnósticos de archivos entre los cuales están tres municipales que conforman la región de la cultura zoque de Chiapas; incluyó propuestas de conservación de documentos históricos en la zona. La etnia zoque ha recibido poca atención de parte de los investigadores porque los

primeros estudios con carácter de rescate se realizaron hasta la década de los 60 del siglo pasado. La carencia estudios se debe, también, a la inexistencia de fuentes de información como son los archivos, necesarios para sustentar parte del pasado de estas poblaciones. 


\section{Resultados}

Los primeros materiales que se publicaron son dos memorias que contienen los rescates archivísticos realizados en Puebla en 2003 y 2004, que representan un gran avance que no se tenía desde la década de los ochenta del siglo pasado. Los inventarios se elaboran a partir de cada archivo organizado y se ponen a disposición de la institución y de los investigadores. De la colección de inventarios de ADABI, se han publicado 338 hasta la fecha: más de 100 corresponden a archivos municipales.

Los inventarios pueden estar en soporte papel, o en CD como el Inventario de documentos virreinales del Archivo Municipal de Tlacotepec de Benito Juárez de 1691 a 1821, el Inventario de documentos del fondo colonial del Archivo Municipal de Libres, que comprende el periodo de 1554-1826 y el Inventario del Archivo Municipal de Tepeaca, de 1811-1945; del estado de Chihuahua el Inventario del Fondo del siglo XIX del Archivo Histórico Municipal de Parral y el Inventario del Archivo Histórico Municipal de Janos, que comienza en 1816.

Bajo el sello editorial de ADABI se han publicado guías y catálogos de archivos municipales, ambos, instrumentos de consulta archivística. El primero presenta al archivo desde un punto de vista global, y el segundo desde una descripción más profunda y específica de una serie documental. Muestra de lo anterior es el Catálogo de Ilustraciones de 1570 a 1890 del Archivo General Municipal de Puebla o la Guía general del Archivo Histórico Municipal de Puebla que contempla 61 series y que cubre un periodo de 1553 a 2005.

Otra publicación de este tipo es la Guía General del Archivo Histórico Eduardo Guerra de Torreón Coahuila, la cual señala que en este archivo hay documentos que proceden del gobierno municipal y otros fondos como son el de Tlahualillo, el de la Comisión de Conurbación de la Laguna, el de Beatriz González de Montemayor, el de Ferrocarril, el de la Compañía Mantequera de Torreón, el del Futbol en la Laguna, además de una Colección de fotografias de 1880 a 2005 y una biblioteca adjunta. Respecto a estudios históricos publicados están los de Cuetzalan 1861-1968, testimonio de un legado documental; Extranjeros en San Andrés 
Chalchicomula, Puebla 1850-1928; Un gran pueblo, una gran historia: Tepetlaxco de Hidalgo y el Valle de Santa Isabel en los siglos XVI y XVII; San Simón Tehualtepec y su archivo municipal y La orografia del Mapa 1 de San Miguel Ixitlán que hace referencia al mapa del siglo XVII que fue encontrado en el rescate de este archivo en octubre de 2013. Como instrumentos de apoyo para el rescate de archivos, en el 2006 se publicó el Manual de organización de Archivos Municipales así como Notas y advertencias para inventariar el archivo municipal, de 2010, ambos necesarios para unificar criterios respecto a la organización.

Gráfica 3. Cronología de los archivos rescatados por ADABI.

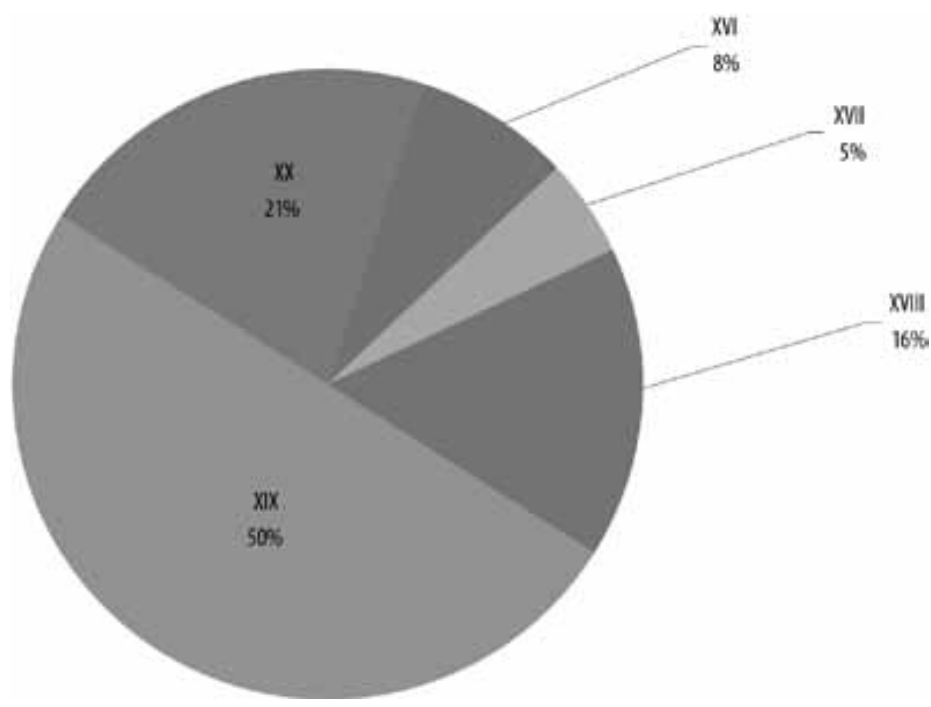

\section{Consideraciones finales}

Rescatar, organizar, inventariar, son verbos que se refieren a acciones desarrolladas en la archivística y en las que ADABI ha centrado su atención para salvaguardar los documentos históricos de los municipios. Los resultados de estas acciones son cada uno de 
los 124 inventarios publicados disponibles para los investigadores o interesados en su consulta. Con los inventarios sentamos las bases para la elaboración de otros instrumentos de descripción como guías o catálogos así como elaboración de artículos de investigación con diferentes enfoques históricos.

Por otra parte, ADABI reconoce que los beneficios de la organización de los archivos no serán inmediatos, ya que tal vez pasen años para que alguna persona pregunte por el archivo municipal. La gratificación vendrá cuando esa persona encuentre los documentos en cajas identificadas en secciones y series haciendo que su tarea de investigación rinda frutos.

En la tarea de rescate, ADABI ha estado acompañada de otras instituciones que comparten el interés por levantar la historia del suelo y uniendo esfuerzos han emprendido proyectos en favor de los archivos municipales, con la ilusión que esta labor se multiplique en los próximos años.

ADABI seguirá en su misión, consciente de que esta tarea dará un giro cuando se le otorgue a los documentos su justo valor de utilidad para el municipio y la comunidad que lo habita, así como para la historia del país. 
Cuadro 1. Listado de archivos municipales rescatados por ADABI 2003-2014

Chihuahua: 8 archivos

De los municipios de Guerrero, Matachí, Cuauhtémoc, Cusihuiriachi, Cerro Prieto, Parral, Janos.

Durango: 1 archivo

Del municipio de Durango.

Guanajuato: 3 archivos

De los municipios de Acámbaro, Irapuato, Salamanca.

Hidalgo: 2 archivos

De los municipios de Apan, Tepeapulco.

Jalisco: 2 archivos

De los municipios de Miguel el Alto, Tequila.

Michoacán: 1 archivo

Del municipio de Tacámbaro de Codallos.

Morelos: 6 archivos

De los municipios de Mazatepec, Yautepec, Miacatlán, Tetela del Volcán, Tepoztlán, Cuautla.

Oaxaca: 27 archivos

De los municipios de Santiago Huajolotitlán, Mixteca Baja, Zacatepec Mixe, Santiago Choapam, Guadalupe Etla, Nazareno Etla, Reyes Etla, San Juan Bautista, Guelache, San Pablo Huitzo, San Pedro y San Pablo, Ayutla, Santa María, Tlahuitoltepec, Santiago Atitlán, Santa María Tepantlali, Mixe, Santa María Tonameca, Teotitlán del Valle, Villa Tejupam de la Unión, Miahuatlán de Porfirio Díaz, Santiago Cacaloxtepec, Asunción Cuyotepeji, Villa de Tamazulapam del Progreso, San Juan Bautista, Guicatlán, Heroica Ciudad de Tlaxiaco, Zapotitlán, San Miguel Villa Talea de Castro, San Pedro y San Pablo, Teposcolula, San Bartolo Soyaltepec, San Andrés Zautla, Santiago Nundiche. 
Puebla: 64 archivos

De los municipios de Tlacotepec de Benito Juárez, Tochimilco, Aljojuca, Amixtlán, San José Chiapa, Zongozontla, Camocuautla, Tepango de Rodríguez, Amozoc de Mota, San Nicolás Buenos Aires, San Juan Atenco, Tlanepantla, San Miguel Xoxtla, San Jerónimo, Xayacatlán, San Felipe Teotlanzingo, Nealtican, Quecholac, Tecali de Herrera, San Salvador el Seco, Santiago Miauhuatlán, Chalchicomula de Sesma, San Salvador el Verde, Cuauhtinchán, Yehualtepec, Acatlán de Osorio, Chila de las Flores, Domingo Arenas, Xochitlán Todos Santos, Tlapanalá, San Miguel Ixitlán, Libres, Tepeaca, Zacapala, Puebla.

San Luis Potosí: 1 archivo

Del municipio de San Luis Potosí.

Sinaloa: 2 archivos

De los municipios de Corcordia, El Fuerte.

Tamaulipas: 4 archivos

De los municipios de González, San Carlos, Jiménez, Tamaulipas.

Tlaxcala: 3 archivos

De los municipios de Apetatitlán de Antonio, Carvajal, Juan Cuamatzi, Ixtenco.

Veracruz: 3 archivos

De los municipios de Orizaba, Camerino Z. Mendoza, Huayacocotla.

Fuente: Elaboración a partir de la información tomada de un registro de archivos municipales de ADABI. 


\section{Bibliografía}

ADABI, Manual de organización de archivos municipales, México, ADABI de México, 2006.

Alanís Boyso, José Luis, "Los archivos municipales del Estado de México, proceso de organización y guía descriptiva", en Historia Mexicana, vol. 28, núm. 4, 1979.

Archivo General de la Nación, El Patrimonio documental oaxaqueño. El rescate de la memoria, México, AGN, 2002.

Arrioja, Luis Alberto, Inventario de Archivos Municipales de Oaxaca, México, AGN, 2002.

Cruz Valdés, Reina, "Fuentes y documentos para la historia de Puebla: programa de rescate, inventario y catalogación de archivos", en Memoria de la IX Reunión, vol. 24, 1986.

Dorantes de Silva, María Teresa, "El estado que guardan el Archivo Histórico del Gobierno del Estado de México y los archivos municipales", en Galeana, Patricia, Balance y perspectiva de los archivos.

Fuster Ruiz, Francisco, "Archivística, archivo, documentos de archivo, necesidad de aclarar los conceptos", en Anales de Documentación, vol. 2, 1999.

González Minchaca, Dámaris, "El Municipio en México", en Revista de la Confederación Estudiantil de Derecho Administrativo Hispanoamericano, núm. 3, 2011.

Hernández Gutiérrez, Misael V., "Hacia un diagnóstico general de los problemas municipales de México", ensayo.

Lozano y Nathal, Gema (coord.), Con el sello de agua. Ensayos históricos sobre Tlacotalpan, México, IVC-INAH, 1991.

Pacheco Zamudio, María del Pilar, Memoria 1, México, ADABI de México, 2004. 
, Memoria 2, México, ADABI de México, 2004.

Ramírez Deleón, José Antonio, Metodología para la organización de sistemas institucionales de archivos (archivos de trámite, de concentración e históricos) México, AgN-IFAI, 2011.

Rodríguez Ochoa, Patricia, Los archivos municipales de Puebla, México, Gobierno del Estado de Puebla- Archivo General de la Nación, 1985.

Salazar Adame, Jaime, "Los archivos municipales mexicanos", en González Oropeza, Manuel, El municipio en México.

Vergara Cruz, Gustavo, Los archivos de Veracruz. Un patrimonio en el olvido, Veracruz, 1995. 